\title{
Hybrid Tea-roses under controlled light conditions. 1. The effect of the level of irradiance on the growth and development of seedlings
}

\author{
D. P. de Vries and L. Smeets
}

Institute for Horticultural Plant Breeding (IVT), Wageningen, the Netherlands

Key words: Rosa, rose, Hybrid Tea, seedling, flower bud, abortion, blind shoot, irradiance level, low light intensity, juvenile period, shoot length, leaf number, leaf area, petal number

\section{Summary}

As a basis for a breeding programme for varieties which are better adapted as regards flowering in winter light conditions, the growth of Hybrid Tea-rose seedlings under controlled conditions was studied. Irradiance varied from $4-24 \mathrm{~W} \mathrm{~m}^{-2}$, day length was 8 hours, temperature $21^{\circ} \mathrm{C}$. Like varieties, Hybrid Tea-rose seedlings may abort the flower bud at low light intensity. With increasing irradiances, the following phenomena were observed: the juvenile period of the seedlings shortened; plants were longer, at bud formation, at first flowering and at flower bud abortion; leaf area and the number of petals increased. Leaf number was constant at all irradiances. Flowering seedlings were smaller at bud formation, but taller at actual flowering than blind ones. Blind seedlings had fewer leaves with a smaller area.

\section{Introduction}

Blindness in roses is the delayed effect of flower bud abortion in an early stage of shoot development (Hubbell, 1934b; Kamp, 1948). Owing to blind shoots growers of cut roses suffer considerable financial losses.

In roses, the abortion of the flower bud can be caused by both low temperature and low light intensity (Moe \& Kristoffersen, 1969; Moe, 1972). Because in greenhouses temperature can be regulated, flower bud abortion there is mainly due to the sun's shorter and less intensive irradiation in autumn and winter.

Although all roses may produce blind shoots, in the same environment large varietal differences in the proportional occurrence are observed (de Vries, 1977). Sofar very few, if any, varieties are good producers in winter, while of the numerous cultural practices to prevent blindness, supplementary lighting only appears to be effective (Carpenter \& Rodriguez, 1971; Carpenter \& Anderson, 1972; Cockshull, 1975; Vonk Noordegraaf, 1976), be it at high costs.

To investigate whether breeding and subsequent selection in seedlings would 
Table 1. Years, number of seedlings, irradiance and light sources used.

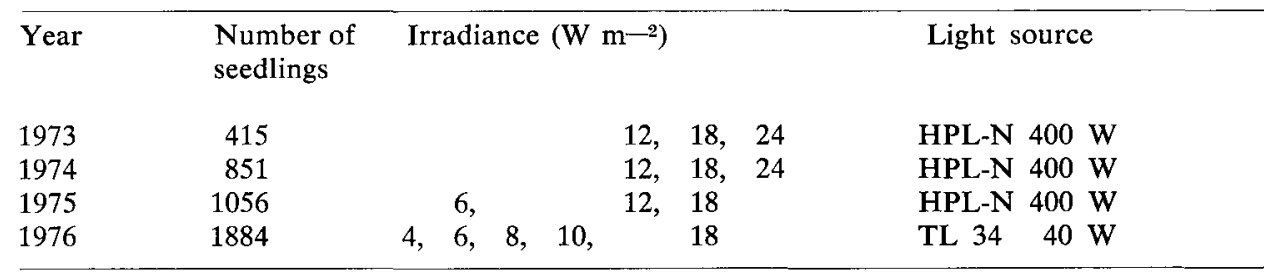

offer possibilities for better winter varieties, seedlings were grown in a phytotron at a series of low light intensities such as occur in our latitude $\left(52^{\circ} \mathrm{N}\right)$ in winter in a greenhouse.

The present paper reports on the effect of the light intensity on the growth of Hybrid Tea-rose seedlings.

\section{Material and methods}

Each spring, from 1973 through 1976, seedlings of Hybrid Tea-rose populations were irradiated by light sources and at energy levels as shown in Table 1, in a growth chamber of the IVT phytotron. Light intensity was measured with a calibrated photocell (type Hartmann \& Braun). From these measurements the amount of visible radiation was calculated. In all trials day length was 8 hours, the temperature about $21{ }^{\circ} \mathrm{C}$.

Each year partly different but closely related seedling populations were produced. Just after germination, generally at the beginning of March, seedlings in the cotyledon stage were transplanted in square $6 \mathrm{~cm} \times 6 \mathrm{~cm}$ plastic pots. They were equally divided over the irradiance levels and placed on benches when 2 true leaflets were present. Particularly in the first two years of the experiments, growing of seedlings at low light intensities resulted in a relatively high mortality. Plants were

Table 2. Observations made in the years indicated.

\begin{tabular}{lcccc}
\hline Observation & 1973 & 1974 & 1975 & 1976 \\
Date of germination & $\times$ & $\times$ & $\times$ & $\times$ \\
Date of flower bud appearance & $\times$ & $\times$ & $\times$ & $\times$ \\
Date of flower bud abortion & $\times$ & $\times$ & - & $\times$ \\
Date of flowering & $\times$ & $\times$ & $\times$ & - \\
Length at bud formation (mm) & $\times$ & $\times$ & $\times$ & $\times$ \\
Length at bud abortion (mm) & $\times$ & $\times$ & - & $\times$ \\
Total length at 1st flowering (cm) & $\times$ & $\times$ & $\times$ & - \\
Number of leaves of flowering seedlings & $\times$ & $\times$ & - & $\times$ \\
Number of leaves of aborted seedlings & $\times$ & $\times$ & - & $\times$ \\
Length of flower stalk & $\times$ & $\times$ & - & - \\
Area of 4th leaf (mm $\left.{ }^{2}\right)$ & - & - & $\times$ & $\times$ \\
Number of petals & - & - & $\times$ & - \\
\hline
\end{tabular}


extremely sensitive to overhead watering and spraying liquids. In the later years the use of HETO irrigation mats for watering and fertilization, and dusting powders for pest control, greatly increased the numbers of surviving plants. Observations and the year in which they were made are presented in Table 2.

Because plants had to be spared for further examination, only the area of the fourth leaf, being the largest one, was measured with an optical planimeter as described by Schurer (1971).

\section{Results}

\section{Flowering seedlings}

For a better understanding of the results of the experiments, in Fig. 1 the graph of an earlier paper (de Vries, 1976) is represented, showing the growth of the leaved shoot, flower stalk and number of leaves of a rose seedling raised in a greenhouse at about $20^{\circ} \mathrm{C}$ in full daylight.

It can be seen that during the first 18 days after germination a rosette of 3-4 true leaflets is being formed just above the cotyledons; from then shoot growth with elongation of the internodes starts. After 27 days the flower bud appears. The juvenile period (JP), defined as the number of days from seed germination to flower bud appearance (de Vries, 1976) has now ended. When the flower bud is present, no further leaves are formed. After flower bud appearance the flower stalk shows a rapid growth; when flowering occurs 54 days after germination, the stalk is slightly longer than its supporting shoot.

The present experiments show that the light intensity has an effect on this growth pattern.

It can be seen in Fig. 2 that irradiance and JP were inversely related. In the first two years of trial when cultivation of the seedlings was still giving difficulties,

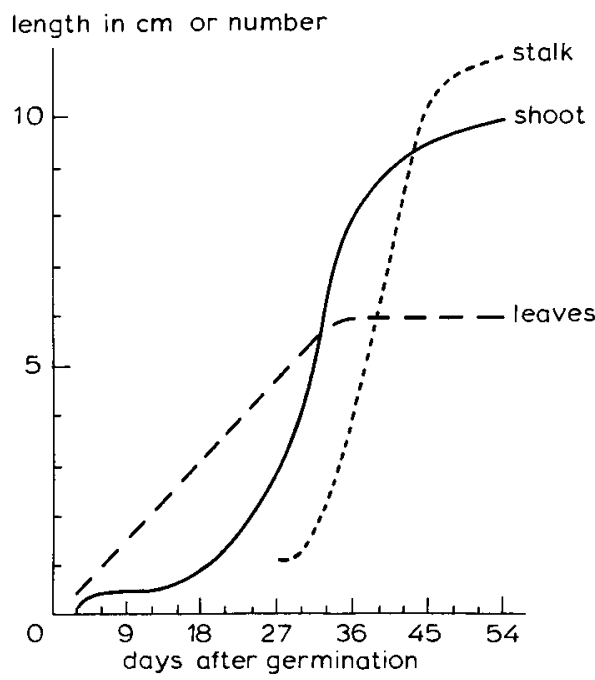

Fig. 1. Development from germination to first flowering of the number of leaves, the leaved shoot and the flower stalk of a Hybrid Tearose seedling (After de Vries, 1976).

Neth. J. agric. Sci. 26 (1978) 


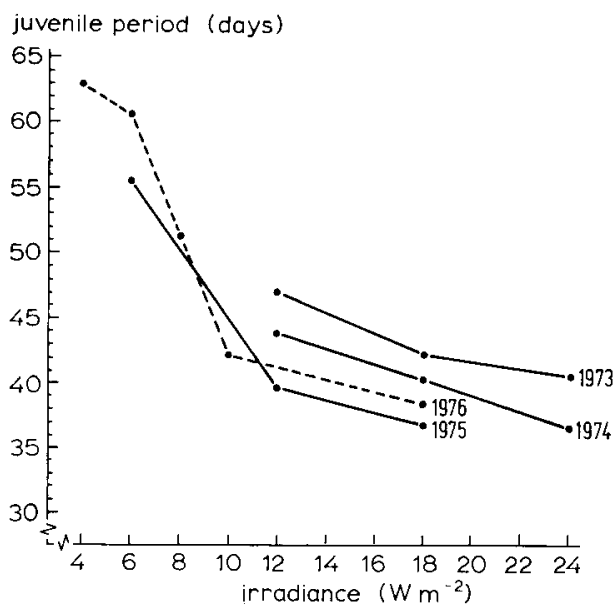

Fig. 2. The relation between the level of irradiance and the juvenile period of Hybrid Tea-rose seedlings.

the JP was somewhat longer at the same irradiance than in 1975 and 1976.

Also the length of the seedling at bud appearance significantly increased with irradiance, as can be seen in Fig. 3 .

Fig. 4 illustrates for one population (Sonia $\times$ Korp) the relation between JP and the length of the seedling at flower bud appearance at various irradiance levels in three years. It can be seen that at each level of irradiance, the lengths of the seedlings increased with the JP. The same relation was found for other populations as well. All correlations were significant.

Fig. 5 illustrates that the number of days from bud appearance to flowering, like the JP, decreases with increasing irradiances. This means that the number of days from germination to flowering also falls of when irradiance increases.

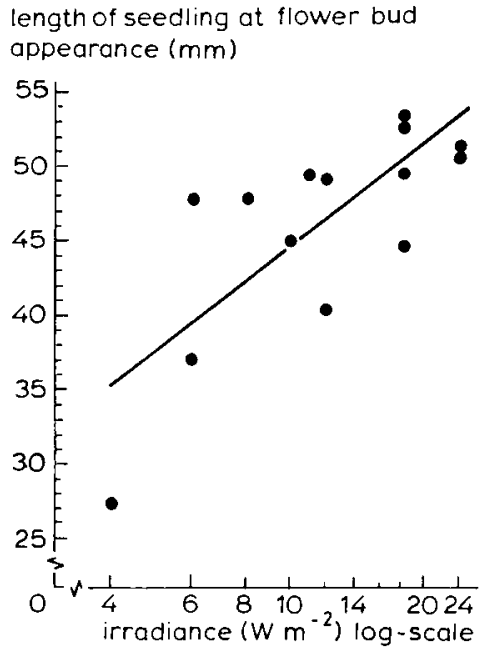

Fig. 3. The relation between the level of irradiance and the length of Hybrid Tea-rose seedlings at flower bud appearance $(r=0.76 ; n=14)$. 


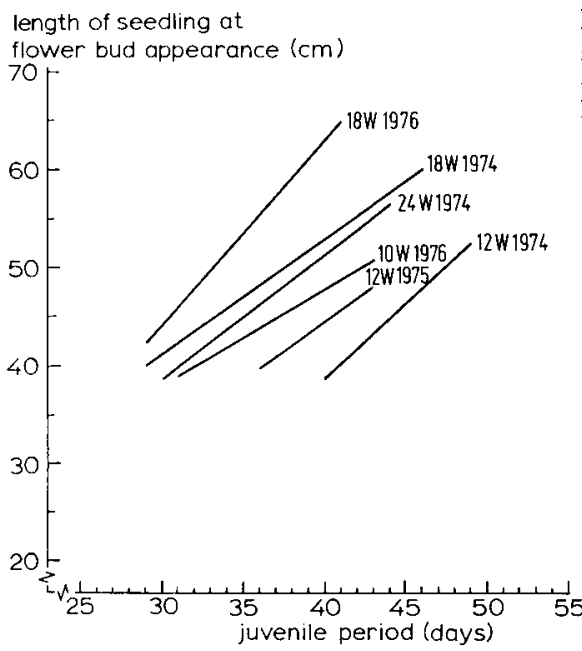

Fig. 4. The relation between the juvenile period and the length of the seedling at flower bud appearance at different light levels, for seedlings of the population Sonia $\times$ Korp in 1974, 1975 and 1976.

Seedling length at flowering increased with irradiance, as can be seen in Table 3. Similarly the length of the flower stalk or 'neck' increased with irradiance.

The number of petals, recorded in 1975 only, increased with irradiance. At 6 , 12 and $18 \mathrm{~W} \mathrm{~m}^{-2}$, petal numbers were $9.6,14.3$ and 17.4 , respectively.

\section{Aborting seedlings}

In each experiment, in a number of seedlings no flower bud appeared when the plants were so far developed that a bud would normally be expected to occur. Such plants did not increase in length any more. When also their leaves neither

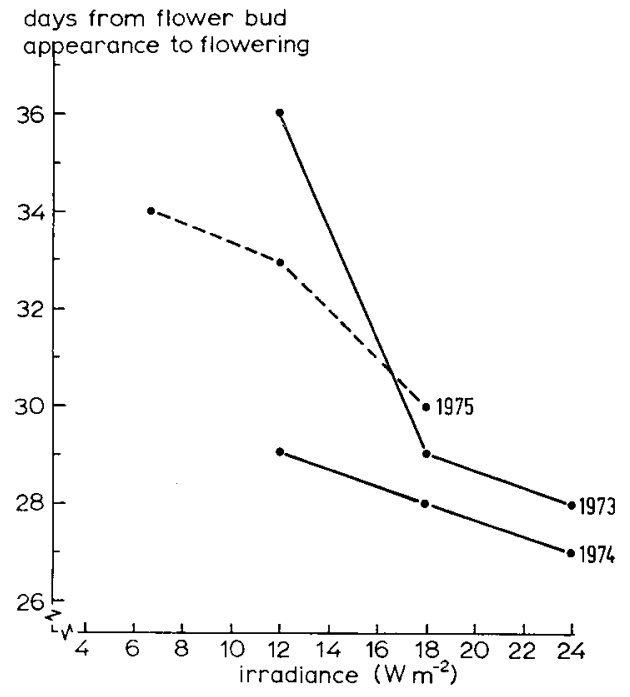

Fig. 5. The relation between irradiance and the number of days from flower bud appearance to flowering of Hybrid Tea-rose seedlings. 


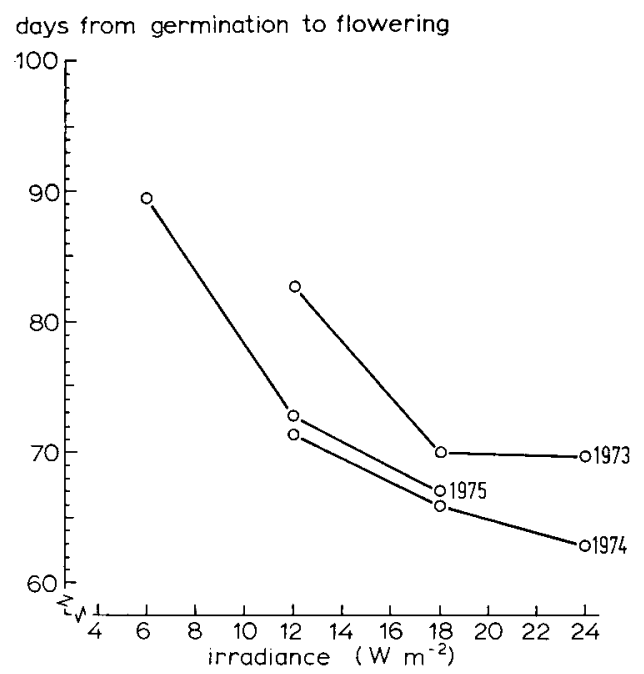

Fig. 6. The relation between irradiance and the number of days from seed germination to flowering of Hybrid Tea-rose seedlings.

increased in number nor in size, and when after some time their upper axillary buds broke, it was clear that seedlings, like varieties, could be blind.

In a number of seedlings a shrivelled flower bud was observed just over the top leaf. Also in a few cases the already present flower bud would still abort, but elongation of the stalk was never observed. The above indicates that also in nonflowering seedlings flower bud initiation may have taken place. The dependence of blindness on the level of irradiance and its occurrence in populations will be considered in Part 2 of this series.

\section{Comparison of flowering and aborting seedlings}

In Table 4 the average number of days from germination to abortion in 1976, being the most accurate, are compared with the average JP's at five irradiances. Similar to the JP and the times from germination to flowering, increasing irradiances induced shorter times to abortion. It can also be seen in the table that at all irradiances the number of days to abortion was longer than the JP. The largest difference occurred at $4 \mathrm{~W} \mathrm{~m}^{-2}$, while on average flower bud abortion was observed 3.9 days later than flower bud appearance.

At most irradiances seedlings were taller at the time of flower bud abortion than at the time of flower bud appearance, but differences were inconsistent and unrelated to irradiance (Table 5). However, when the plants with a bud flowered, the

Table 3. Average lengths ( $\mathrm{mm}$ ) of shoots and of flower stalks of Hybrid Tea-rose seedlings at four irradiances in 1974 and 1975.

\begin{tabular}{llccc}
\hline & $6{\mathrm{~W} \mathrm{~m}-^{-2}}$ & $12 \mathrm{~W} \mathrm{~m}^{-2}$ & $18 \mathrm{~W} \mathrm{~m}-2$ & $24 \mathrm{~W} \mathrm{~m}-^{2}$ \\
Shoot & 13.2 & 14.5 & 15.8 & 16.2 \\
Stalk & - & 5.7 & 6.7 & 7.0 \\
\hline
\end{tabular}


Table 4. Juvenile periods and number of days to abortion of Hybrid Tea-rose seedlings at five irradiance levels in 1976.

\begin{tabular}{|c|c|c|c|c|c|c|}
\hline & $4 \mathrm{~W} \mathrm{~m}^{-2}$ & $6 \mathrm{~W} \mathrm{m-2}$ & $8 \mathrm{~W} \mathrm{~m}^{-2}$ & $10 \mathrm{~W} \mathrm{~m}^{-2}$ & $18 \mathrm{~W} \mathrm{~m}^{2}$ & Average \\
\hline Juvenile period & 62.8 & 61.6 & 51.2 & 42.0 & 38.4 & 51.2 \\
\hline $\begin{array}{l}\text { Number of days } \\
\text { to abortion }\end{array}$ & 72.7 & 64.2 & 54.6 & 42.5 & 41.6 & 55.1 \\
\hline Difference & 9.9 & 2.6 & 3.4 & 0.5 & 3.2 & 3.9 \\
\hline
\end{tabular}

Table 5. Average lengths $(\mathrm{mm})$ at flower bud appearance and flower bud abortion of Hybrid Tea-rose seedlings at various levels of irradiance in 1974 and 1976.

\begin{tabular}{|c|c|c|c|c|c|c|c|c|}
\hline & $\begin{array}{l}4 \\
W m^{-2}\end{array}$ & $\begin{array}{l}6 \\
W m-2\end{array}$ & $\begin{array}{l}8 \\
W \text { m-2 }\end{array}$ & $\begin{array}{l}10 \\
W_{m-2}\end{array}$ & 12 & $\begin{array}{l}18 \\
W \mathrm{~m}=2\end{array}$ & $\begin{array}{l}24 \\
\mathrm{~W} \text { m-2 }\end{array}$ & Average \\
\hline $\begin{array}{l}\text { Flower bud } \\
\text { appearance } \\
\text { Flower bud }\end{array}$ & 27.0 & 37.0 & 48.0 & 45.0 & 46.5 & 50.1 & 51.6 & 43.6 \\
\hline abortion & 26.0 & 39.0 & 62.0 & 42.0 & 52.0 & 59.7 & 67.0 & 49.7 \\
\hline Difference $(\%)$ & -4 & +5 & +23 & -7 & +11 & +16 & +23 & +12 \\
\hline
\end{tabular}

Table 6. Average lengths $(\mathrm{cm})$ of the leaved part of flowering and of aborting Hybrid Tea-rose seedlings at four levels of irradiance in 1974 and 1975.

\begin{tabular}{|c|c|c|c|c|c|}
\hline & $6 \mathrm{~W} \mathrm{m-2}$ & $12 \mathrm{~W} \mathrm{~m}^{-2}$ & $18 \mathrm{~W} \mathrm{~m}-2$ & $24 \mathrm{~W} \mathrm{~m}-2$ & Average \\
\hline Leaved shoot & 8.5 & 8.8 & 9.1 & 9.7 & 9.0 \\
\hline Aborted shoot & 3.9 & 5.2 & 6.0 & 6.7 & 5.5 \\
\hline Difference $(\%)$ & 54 & 41 & 34 & 31 & 39 \\
\hline
\end{tabular}

Table 7. Leaf numbers of flowering and aborting Hybrid Tea-rose seedlings at various levels of irradiance in 1974 and 1976.

\begin{tabular}{|c|c|c|c|c|c|c|c|c|}
\hline & 4 & 6 & $\begin{array}{l}8 \\
W ~ m-2\end{array}$ & $\begin{array}{l}10 \\
\mathrm{~W} \mathrm{m-2}\end{array}$ & $\begin{array}{l}12 \\
W m-2\end{array}$ & 18 & $\begin{array}{l}24 \\
W m^{2}\end{array}$ & Average \\
\hline Flowering plants & 5.9 & 6.6 & 6.5 & 6.0 & 5.8 & 6.0 & 5.9 & 6.1 \\
\hline Aborted plants & 5.9 & 6.1 & 6.3 & 5.5 & 5.6 & 5.9 & 5.6 & 5.8 \\
\hline Difference & 0.0 & 0.5 & 0.2 & 0.5 & 0.2 & 0.1 & 0.3 & 0.3 \\
\hline
\end{tabular}

Table 8. Area of the 4 th leaf $\left(\mathrm{mm}^{2}\right)$ of flowering and aborting Hybrid Tea-rose seedlings at four levels of irradiance in 1975 and 1976.

\begin{tabular}{|c|c|c|c|c|c|}
\hline $\begin{array}{l}\text { Category of } \\
\text { seedlings }\end{array}$ & $6 \mathrm{~W} \mathrm{m-2}$ & $10 \mathrm{~W} \mathrm{~m}-2$ & $12 \mathrm{~W} \mathrm{~m}-2$ & $18 \mathrm{~W} \mathrm{m-2}$ & Average \\
\hline Flowering & 581 & 1080 & 1100 & 1120 & 970 \\
\hline Aborted & 532 & 950 & 1050 & 1080 & 903 \\
\hline Difference (\%) & 8.5 & 12.0 & 5.0 & 4.0 & 7.0 \\
\hline
\end{tabular}

Neth. J. agric. Sci. 26 (1978) 
leaved part of their shoot was at all irradiances considerably longer than the aborted shoots (Table 6). Differences tended to decrease with increasing irradiances.

In both flowering and aborted plants the average number of leaves was not affected by the level of irradiance (Table 7). Differences in leaf number between flowering and aborted plants were small and apparently not affected by the level of irradiance. Aborted plants had on average 0.3 leaf less than flowering ones, which means that about one out of three seedlings with an aborted bud had one leaf less than the flowering plants.

As can be seen in Table 8, the area of the 4th leaf in both flowering and aborted seedlings increased with irradiance. At all levels of irradiance leaf areas of flowering seedlings were slightly larger than those of aborted ones. The fourth leaf was on average about $7 \%$ smaller in aborted than in flowering seedlings. Differences between the two categories tended to become smaller with increasing irradiances.

\section{Discussion and conclusions}

The present experiments did not show any essential differences between the reactions to the light intensity of flowering and aborting rose seedlings. Thus with increasing light intensity in all seedlings the length of the plants and their leaf area increased. In flowering seedlings the numbers of days from germination to bud appearance and to flowering shortened, and the number of their petals increased. Also in aborting plants the number of days to flower bud abortion decreased.

In varieties too, Moe \& Kristoffersen (1969), Moe (1972) and Khosh-Khui \& George (1976) found that the times from cut-back to flowering, which may be compared with the times from germination to flowering in seedlings, decreased with increasing irradiances. Contrary to seedlings, the number of petals in the variety 'Baccara' was not affected by light intensities increasing from 2000 to 10000 lux (Moe \& Kristoffersen, 1969). Also the lengths of flowering 'Baccara' shoots were not influenced by irradiance, but its number of leaves decreased with increasing irradiances (Moe, 1971).

At each level of irradiance, seedlings bore about 6 leaves. As the same number was found in seedlings grown in full daylight (de Vries, 1976), this may indicate that leaf number in Hybrid Tea-rose seedlings is an inherent juvenile character and as such insensitive to irradiance.

At each energy level consistent differences between flowering and aborted seedlings occurred, i.e. aborted shoots were shorter and bore fewer and smaller leaves than the flowering ones. In all varieties investigated flowering shoots were also longer and bore more leaves than aborted ones (Hubbell, 1934a; Kamp, 1948; Moe, 1971). Apparently in both seedlings and varieties, abortion was not confined to the flower bud. Because, in varieties more top leaves were missing than in seedlings, it is probable that in varieties abortion occurs earlier than in seedlings.

From the foregoing it appears that seedlings and varieties do not react in all aspects similarly to the light intensity. This might be the consequence of slight differences in the environments of our trials and those mentioned in literature. On the other hand there is the possibility that roses in the juvenile phase in certain aspects 


\section{HYBRID TEA-ROSES UNDER CONTROLLED LIGHT CONDITIONS. 1}

react differently to light than when adult. Before it can be ascertained whether the reactions of seedlings are essentially different from those of varieties, further research is necessary.

\section{References}

Carpenter, W. J. \& R. C. Rodriguez, 1971. Supplemental lighting effects on newly planted and cut-back greenhouse roses. Hort Science 6: 207-208.

Carpenter, W. J. \& G. A. Anderson, 1972. High intensity supplementary lighting increases yields of greenhouse roses. J. Am. Soc. hort. Sci. 97: 331-334.

Cockshull, K. E., 1975. Roses II: The effects of supplementary light on winter bloom production. J. hort. Sci. 50: 193-206.

Hubbell, D. S., 1934a. Causes of blind wood in roses. Pl. Physiol. 9: 261-282.

Hubbell, D. S., 1934b. A morphological study of blind and flowering rose shoots with special reference to flower bud differentiation. J. agric. Res. 48: 91-95.

Kamp, J. R., 1948. The incidence of blindness in the Better Times rose. Proc. Am. Soc. hort. Sci. 52: 490-500.

Khosh-Khui, M. \& R. A. T. George, 1976. Responses of glasshouse roses to light conditions. Scientia Hort. 6: 223-235.

Moe, R., 1971. Factors affecting flower abortion and malformation in roses. Physiologia Pl. 24: $291-300$.

Moe, R., 1972. Effect of daylength, light intensity, and temperature on growth and flowering in roses. J. Am. Soc. hort. Sci. 97: 796-800.

Moe, R. \& T. Kristoffersen, 1969. The effect of temperature and light on growth and flowering of rosa 'Baccara' in greenhouses. Acta Hort. 14: 157-166.

Schurer, K., 1971. Direct reading optical leaf area planimeter. Acta bot. neerl. 20: 132-140.

Vonk Noordegraaf, C., 1976. Supplementary lighting at the rose cv 'Sonia'. Acta Hort. 64: 155-164.

Vries, D. P. de, 1976. Juvenility in Hybrid Tea-roses. Euphytica 25: 321-328.

Vries, D. P. de, 1977. Shoot production in cut roses with reference to breeding for winter flowering. Euphytica 26: 85-88. 